\title{
Prometheus unbound, at last
}

\section{And not a moment too soon.}

\section{Kim Stanley Robinson}

\section{Please append your report here}

This novel postulates that science is an ongoing utopian proto-political experiment poorly theorized as such and lacking a paradigm within which to exert power in human affairs commensurate with its actual productive capacity and lifemaintenance criticality. Scientists are furst seen marginalized from macro-decisionmaking in a backstory (written in the style of a Cold War thriller) in which agents sequester science by convincing Truman et al. that science's metastasizing wartime ability to create new technologies crucial to victory (radar, penicillin, atom bomb, etc.) might constitute a threat to postwar civiliancorporate control of society.

Scientists, subsequently inoperative in surplus value investment and allocation decisions, produce goods and services unconscious of themselves as a group and individually willing to work within the existing hierarchical extractive nonsustainable system for $\$ 100,000 \pm$ 50,000 annually plus pension, stock options and a light teaching load. (This chapter is in the form of a zombie novel, highly amusing.)

Then the scientifically augmented human population catastrophically overshoots the long-term carrying capacity of the planet. Scientists in their various toothless non-decision-making organizations conclude that the anthropogenically initiated climate change, and mass extinction event associated with it, probably threatens their descendants' welfare, and thus scientists' own evolutionary fitness. The sleepers awake.

Meanwhile a certain proportion of humanity makes a cost-benefit analysis comparing 15 years' work learning a science with saying "I believe" and through group political action controlling more calories per capita than scientists do, also more power over funding and rather more offspring. Many conclude faith-based parasitism on science less costly to the individual, so more adaptive. (Vampires living off zombies, guns brandished, chases by night: the novel gets pretty lurid at this point.)

Then at a modelling conference a discussion springs up concerning Hamilton's rule, which states that altruism should evolve whenever the cost to the giver, $C$, is less than the fitness benefits, $B$, obtained by helping another individual who is related by $r$, with $r$ being calculated as the proportion of genes these two individuals share by common descent (as in Hrdy, 1999): C $\leqslant B r$.

A geneticist at the conference points out that as humans share $60 \%$ of their genes with fruitflies, and all eukaryotes share 938 core genes, $r$ is probably always higher than heretofore calculated. An ecologist mentions the famous Nature article in which the benefits provided by the biosphere to humans were estimated at $\$ 33$ trillion a year (R. Costanza et al. Nature 387, 253-260; 1997). An economist suggests that the cost for individual scientists wanting to maintain these benefits could be con- most of the novel's sex scenes. Author seemingly familiar with and perhaps overfond of the bonobo literature. Strenuous attempts to maximize reproductive success in Davos, Santa Fe, Las Vegas, etc.

Novel's style shifts to amalgam of legal thriller and tolkienesque high fantasy as scientists take power from corporate military-industrial global élite. A spinradian strategic opacity here obscures the actual mechanism that would allow this to workin the real world, said opacity created by deployment of complicated syntax, phrases low in semantic content ("information cascade"), especially active stage business (man runs through with hair on fire), explosions, car chases, and reinvocation of Very Big Numbers - in this case Science Mutual's potential assets if World Court returns positive judgment, after which subsequent chapter (with toll-free number as epigraph!) emerges in newly utopian space, looking plausible to those still suspended in coleridgean willed non-disbelief.

Speed of narration accelerates. Science Mutual arranges winners in all elections everywhere. Hedge fund continues to grow. Scientific organizations form international supra-organization.

Black helicopters proliferate. Entire ceptualized in the form of a mutual hedge fund, with initial investment set for the sake of discussion at $\$ 1,000$ per scientist.

Comic scene here as modellers debate the numbers, with a biologist pointing out that the benefit of life to every living organism could justifiably be defined as infinity, considerably altering equation's results. (Shouting, fights, saloon demolished in Wild West manner.

Conference attendees conclude altruism is probably warranted, and hedge fund is established. (Readers of novel wishing to pre-invest are directed to a website www.sciencemutualnet.) Participating scientists then vote to establish a board; a model constitution for all governments to adopt; a policy-research institute tasked with forming a political platform; and a lobbying firm. All scientific organizations are urged to join the fund. Fund's legal team goes to World Court to claim compensation for all future biospheric damage, to be paid into the fund by those wreaking the damage and the gowernments allowing it.

Many meetings follow, no doubt explaining the presence in this chapter of population decides to follow new scientific guidelines indicating that reproductive fitness is maximal the closer behaviour conforms to palaeolithic norms, this being the lifestyle that tripled brain size in only $\mathbf{1 . 2}$ million years. Widespread uptake of this behavioural set augmented by appropriate technology (especially dentistry) reduces global resource demand by an order of magnitude despite demographic surge to UN-predicted mid-range peak of ten billion humans. A rationally balanced positive feedbackloop into maximized universal fitness obtains. (Novel ends with standard finale, singing, dancing, reproducing. All Terran organisms live optimally ever after)

\section{Please give your recommendation}

Reader recommends acceptance for publication, but suggests that the apparent size of the text's strategic opacity be reduced to three seconds of arc or less. Publisher should take steps to secure domain name sciencemutual.com. (Also, more car chases.) Kim Stanley Robinson's next novel Fifty Degrees Below, sequel to Forty Signs of Rain, will be published by HarperCollins in September. 